YANFEI TIAN, Ph.D. candidate ${ }^{1,2}$

(Corresponding author)

E-mail: feifei_whut@163.com

XUECHENG SUN, M.Eng. ${ }^{3}$

E-mail: 1061958377@qq.com

LIJIA CHEN, Ph.D.1,2

E-mail: navisky@qq.com

LIWEN HUANG, Ph.D. 1,2 $^{2}$

E-mail: Iwhuang@whut.edu.cn

${ }^{1}$ School of Navigation, Wuhan University of Technology

No. 1178, Heping Ave., Wuchang Dist.,

Wuhan 430063, China

2 Hubei Key Laboratory of Inland Shipping Technology

No. 1178, Heping Ave., Wuchang Dist.,

Wuhan 430063, China

${ }^{3}$ Nansha Department, Guangzhou Marine Safety

Administration, No. 620, Port Ave.,

Nansha Dist., Guangzhou 511458, China
Safety and Security in Traffic

Preliminary Communication

Submitted: 22 Aug. 2016

Accepted: 15 Feb. 2017

\title{
RISK ASSESSMENT OF NAUTICAL NAVIGATIONAL ENVIRONMENT BASED ON GREY FIXED WEIGHT CLUSTER
}

\begin{abstract}
In order to set up a mathematical model suitable for nautical navigational environment risk evaluation and systematically master the navigational environment risk characteristics of the Qiongzhou Strait in a quantitative way, a risk assessment model with approach steps is set up based on the grey fixed weight cluster (GFWC). The evaluation index system is structured scientifically through both literature review and expert investigation. The relative weight of each index is designed to be obtained via fuzzy analytic hierarchy process (FAHP); Index membership degree of every grey class is proposed to be achieved by fuzzy statistics (FS) to avoid the difficulty of building whiten weight functions. By using the model, nautical navigational environment risk of the Qiongzhou Strait is determined at a "moderate" level according to the principle of maximum membership degree. The comprehensive risk evaluation of the Qiongzhou Strait nautical navigational environment can provide theoretical reference for implementing targeted risk control measures. It shows that the constructed GFWC risk assessment model as well as the presented steps are workable in case of incomplete information. The proposed strategy can excavate the collected experts' knowledge mathematically, quantify the weight of each index and risk level, and finally lead to a comprehensive risk evaluation result. Besides, the adoptions of probability and statistic theory, fuzzy theory, aiming at solving the bottlenecks in case of uncertainty, will give the model a better adaptability and executability.
\end{abstract}

\section{KEY WORDS}

nautical navigational environment; risk evaluation; grey fixed weight cluster; fuzzy analytic hierarchy process; fuzzy statistic;

\section{INTRODUCTION}

\subsection{Research background}

Maritime risk is one of the most important focus areas for waterway transportation. Researchers and maritime authorities have been paying special attention to the risky areas where traffic density is high for a long time. The high density and high risk for transportation increase the complexity of navigation safety management [1].

Nowadays, lots of theories and models have been developed for maritime risk assessment. The concept of risk management gives risk assessment priority over taking response measures after an accident [2]. Reasonable and effective risk assessment and prediction of vessel traffic system have been studied in depth [3].

There is no doubt that it is of great significance to evaluate nautical navigation environment appropriately, which demands enough of the original data, proper theories, and suitable mathematical models, etc. Related studies $[4,5]$ show that the grey clustering decision-making, which is an important component of grey theory, is suitable for cluster analysis in case of a lack of data or object information. Given the above views, a grey fixed weight cluster (GFWC) model with implementation scheme will be established in this paper for comprehensive risk assessment of nautical navigational environment. Whereby: (1) as the fundamental step when carrying out an evaluation work, the evaluation index system is designed to be structured scientifically through literature review and expert investigation, (2) as one of the indispensable components, relative weight of each 
index is planned to be calculated based on fuzzy analytic hierarchy process (FAHP), (3) as another indispensable component, index membership degree of every grey class is proposed to be obtained by fuzzy statistics (FS). Then from the point of research task, the proposed model together with the bottleneck solutions will be applied to evaluate the risk of Qiongzhou Strait nautical navigational environment. The comprehensive risk evaluation result aims to provide a scientific reference for decision-making in risk prevention /disaster mitigation.

\subsection{Review on the grey fixed weight cluster based studies}

The grey system theory is a discipline originally put forward by Prof. Deng Julong [6-8] from the Huazhong University of Science and Technology in the 1980s, which provides an effective theory and method to study the system of fewer data, poor information.

Due to the relatively small number of data samples, the relatively low reliability of the data quality, high uncertainty of the decision-making system in the data information, grey system theory has unique advantages to deal with the difficulties. As one of the significant components of grey system theory, the grey fixed weight cluster method has been widely applied over the years to the field of decision-making, such as risk assessment, environmental quality assessment, and the water quality analysis, etc. Shao et al. [9] assessed the rainstorm and flood disasters risk in China based on the fixed weight grey cluster in grey theory. Xie et al. [10] proposed the fixed weight grey cluster model for international cooperation project selection, showing that the method was effective. Based on the grey fixed weight clustering analysis of grey system theory, Luo et al. [11] proved several polysulfonamide (PSA) blended fabric with excellent comprehensive performance, and provided a basis for the selection of thermal protective clothing fabrics. Hu et al. [12] applied the grey clustering model to evaluate the ambient air quality in Fuzhou city from 2004 to 2008, believing that improved grey clustering analysis evaluations are more objective and accurate. He et al. [13] proposed a grey fixed weight clustering based trust model to determine the trust to the witness in Multi-Agent System. Taking in its advantages, Li et al. [14] calculated the informatization benefits with grey clustering method on combinative weight-fixing to evaluate manufacturing enterprise informatization. Combined with Dempster-Shafer theory to overcome the disadvantages of computing the attributes weight in multi-attribute decision problem, Hua et al. [15] used the grey fixed weight cluster method for design scheme selection and illustrate the practicality and effectiveness of the proposed process. Combining the analytic hierarchy process (AHP) and grey clustering analysis, Tang and Li [16] created meteorological disaster post-assessment methods for highway traffic during flood seasons. Hu et al. [17] used the grey system to assess the quality of drinking water in Jiaozuo city, in which the method was simple and the operability was not bad and therefore achieved good results. Jiao and Ma [18] comprehensively evaluated water in the Changjiang River based on grey-fuzzy clustering analysis. On the basis of comprehensive consideration of various disaster loss indicators, Wang et al. [19] made agricultural drought disaster situation assessments and draw regionalization map in the usage of grey fixed weight clustering method, together with the geographic information system (GIS) technological, AHP and triangle whitening weight functions. Aiming at the key problem of the development cost of air-defence missile weapon system, Zhang et al. [20] realized an optimization idea of the development cost based on grey fixed weight clustering. Hu et al. [21] recognized the six kinds of wear debris by using grey fixed weight clustering method, which was helpful to pre-diagnose the faulty type of machinery. Jian et al. [22] selected the regional key technology based on the hybrid model of grey fixed clustering and variable precision rough set, in case that in many uncertain practical decisions data set could only build knowledge presentation system but could not generate decision tables. Zhang and Diao [23] made comprehensive grey cluster evaluation of the university core competence by using fixed weight method, and provided in addition a new judgment standard in order to evaluate its core competitiveness. Zhu and Wang [24] analyzed the pollutant impact on indoor air quality, achieving grey evaluation in indoor air quality. Ip et al. [25] applied the grey correlation degree to water environmental quality assessment. Zhang et al. [26] combined the grey fixed weight clustering method with the levelled eigenvalue to evaluate the growth vigour of 16 cities in the district and then work out the categories regarding the development of their vigour. Wang and Wang [27] successfully made a regional cluster for the 2005 development situation of the research and development (R\&D) industry in China using the grey fixed weight clustering model, where an entropy weight method was adopted to calculate the index weight. By combining the grey fixed-weight clustering method with the levelled eigenvalue method, Zhang et al. [28] evaluated the growth vigour of 19 central cities in China and then work out the energy categories to which they respectively belong. After analysing the three principal factors in terms of economy, society, and environment, Li et al. [29] set up a synthetic index system measuring the sustainable development capacity of the 16 central cities located in the Yangtze River Delta Area and made an overall evaluation accordingly by applying the method combining grey fixed weight clustering with levelled eigenvalue. Lin et al. [30] employed the grey decision-making method to evaluate green engineering and proposed a green ecological evaluation system for Taiwan. Embedded with interval numbers and information entropy, Wang et al. [31] 
proposed a syncretic, feasible and rational method based on grey fixed-weight cluster, which could deal with the conditions better when meanings and dimensions of indicators were different and numerical values had big disparity between each other, and confirm weights of clustering indicators with interval number. Zhang et al. [32] presented a synthetic index system to appraise the urban sustainable development level with respect to economy, society, and environment, and then evaluate the sustainable development level of 18 central cities in China by combining the grey fixed-weight clustering method with the levelled eigenvalue method. Based on grey fixed weight clustering and white-ionization weight function, Nie et al. [33] proposed a kind of grey cluster assessment method for determining the rational open-pit limit of mining, which succeeds in obtaining the better and optimal open-pit-stages limit design. Mi et al. [34] carried out the corresponding algorithm of grey fixed weight clustering decision-making based on entropy weight. The practical problem as empirical study indicated that the method exhibited better effect and could be an effective development to grey clustering decision-making theory. Owing to the grey characteristic of traffic safety information and road factors, $\mathrm{Xu}$ et al. [35] utilized the grey fixed weight cluster method to categorize higher-class highways in a district into several safety grades, and demonstrated that it could perspicuously and accurately reflect the influences of road factors on traffic safety in a complicated system. Li et al. [36] pointed out the limitations of the basic grey fixed weight clustering model, and put forward a dynamic evaluating model for grey clustering based on the relative partition. The model test showed that it could not only effectively analyse the time-span grey clustering, but also employ sufficiently the information from a timespan with little computation. Liu and Wang [37] used grey clustering analysis to analyse the dump-leaching impact on groundwater quality. Yu [38] established an index system and cluster with fixed weights to analyse the efficiency of China commercial banks, introducing meaningful conclusions and suggestions about the bank industry of China. He et al. [39] studied the application of the grey clustering decision in a comprehensive evaluation of water quality.

In view of previous contributions, it can be believed that the grey fixed weight cluster method in grey theory provides an effective approach to decision-making related researches (e.g. clustering analysis, mode recognition, risk assessment, solution selection, etc.) encountering poor data information.

\subsection{Summarized general process to deliver risk evaluation}

Comprehensive evaluation is a work that makes a qualitative and quantitative assessment of certain attribute(s) of the object(s), using a number of indicators.
Combined with both the practical work and literature contributions, the following general framework containing the main five steps is summarized to deliver a quantitative and comprehensive risk evaluation:

1) Choose the appropriate evaluation indices to constitute the index system.

2) Calculate the index weight based on a theoretical model.

3) Quantize risk level of each single index based on a theoretical model.

4) Build a comprehensive mathematical evaluation model based on suitable theory or theories.

5) Compute the evaluation result.

\section{PRINCIPLES OF GREY FIXED WEIGHT CLUSTER}

Grey clustering decision-making is an important component of grey theory. It is suitable for cluster related analyzing when encountering a situation of lack of data and object information. The GFWC method, one kind of grey clustering decision-making methods, is more commonly used in engineering. Symbol definitions and GFWC model are presented below.

The clustering object set

Suppose there are $\mathrm{m}$ objects to be clustered, then the clustering object set is expressed as:

$O=\left\{O_{1}, O_{2}, O_{3}, \ldots, O_{i}, \ldots, O_{m}\right\}$

The clustering indicator set

Suppose the indicator system includes $n$ indicators, then the clustering indicator set is expressed as:

$U=\left\{U_{1}, U_{2}, U_{3}, \ldots, U_{j}, \ldots, U_{n}\right\}$

Indicator characteristic

Variable $x$ is introduced to indicate indicator characteristic. Specifically, symbol $x_{i j}$ is used to define the observation value of $j$-th indicator (or called "indicator $j$ ") about $i$-th object (or called "object $i$ ").

Grey classification set used to describe risk level

Suppose there are I grey classes used to describe risk level, then the grey classification set is expressed as:

$G=\left\{G_{1}, G_{2}, G_{3}, \ldots, G_{k}, \ldots, G_{l}\right\}$

Whiten weight function

The whiten weight function is indicated by $f_{j}^{k}(\cdot)$. Based on the characteristic of the indicator (or called "index") about a cluster object, whiten weight function is used to evaluate the indicator: to get the membership degree of the indicator belonging to different grey classes.

Now follows a brief description of what a GFWC model is after giving the above definitions.

Let $x_{i j}$ be observations of indicators $j$ about object $i$, and $f_{j}^{k}(\cdot)$ is the whiten weight function for the $k$ 
subclasses of the $j$-th indicator; where: $i \in O=\{1,2,3, \ldots, m\}$, $j \in U=\{1,2,3, \ldots, n\}, k \in G=\{1,2,3, \ldots, l\}$.

If weight $\eta_{j}^{k}$ is irrelevant to $k$, that is, for any $k_{1}$ and $k_{2}, \eta_{j}^{k_{1}}=\eta_{j}^{k_{2}}$, then the superscript $k$ can be removed from $\eta_{j}^{k}$. Thus, denote $\eta_{j}^{k}$ as $\eta_{j}$, and take

$$
\sigma_{i}^{k}=\sum_{j=1}^{n} f_{j}^{k}\left(x_{i j}\right) \cdot \eta_{j}
$$

as the grey fixed weight cluster coefficient for judging the object. According to the value of the weighted clustering coefficient, the studied objects can be classified to the corresponding grey classes, which namely approaches the comprehensive assessment.

So, the above evaluation work is known as GFWC.

\section{PROPOSED STEPS TO RISK EVALUATION BASED ON GFWC}

From those stated in Section 2, it can be seen that to achieve risk evaluation based on GFWC in practice, some theoretical models are needed to calculate the index weight (aiming at getting $\eta_{j}$ ) and quantize the risk level of each single index (aiming at getting $f_{j}^{k}\left(x_{i j}\right)$ ). Specifically, the Fuzzy Analytic Hierarchy Process (FAHP) and Fuzzy Statistics (FS), whose basic principles and why they are introduced will be outlined later (mainly in Section 4), are adopted respectively to achieve the mentioned two sub-goals in this paper. Then under the general framework summarized in 1.3, the developed general risk assessment steps based on grey fixed weight cluster are stated as follows:

Step 1: Structure the index system including total $n$ indices;
Step 2: Use FAHP to calculate the subjective weight of each index $\left(\eta_{j}\right)$;

Step 3: Evaluate each index to get the judgement matrix quantized by $r_{i j}^{k}$;

Let $r_{i j}^{k}$ be the membership to the $k$-th grey class about the $j$-th index, where subscript $i$ indicates the $i$-th evaluation object. Then $r_{i j}^{k}$ is capable of expressing the risk level judgement of the related index. Approach to $r_{i j}^{k}$ will be outlined in 4.2.

Step 4: Replace the whiten weight function based single factor judgement $f_{j}^{k}\left(x_{i j}\right)$ by $r_{i j}^{k}$;

The whiten weight value $f_{j}^{k}\left(x_{i j}\right)$ is replaced by $r_{i j}^{k}$ in order to ensure the implementation of the subsequent steps in the grey fixed weight cluster model. The core of the idea can be presented by Formula 2:

$f_{j}^{k}\left(x_{i j}\right)=r_{i j}^{k}$

Step 5: Calculate the grey fixed weight cluster coefficients;

Generally speaking, the coefficients can be calculated via Equation 1. Since in Step $4 f_{j}^{k}\left(x_{i j}\right)$ is replaced by $r_{i j}^{k}$, then the coefficients can be directly calculated by Equation 3:

$\sigma_{i}^{k}=\sum_{j=1}^{n} r_{i j}^{k} \cdot \eta_{j}$

Step 6: Obtain the clustering vector $\sigma_{i}=\left[\sigma_{i}^{1} \sigma_{i}^{2} \sigma_{i}^{3} \ldots \sigma_{i}^{k} \ldots \sigma_{i}^{\prime}\right]$;

Step 7: Find the biggest element $\sigma_{i}^{k^{*}}$ among $\sigma_{i}\left(\sigma_{i}^{k^{*}}=\max _{1<k \leq 1}\left\{\sigma_{i}^{k}\right\}\right)$, and then the $i$-th object is determined belonging to the grey class numbered by $k^{*}$.

The diagram of the above steps is shown in Figure 1.

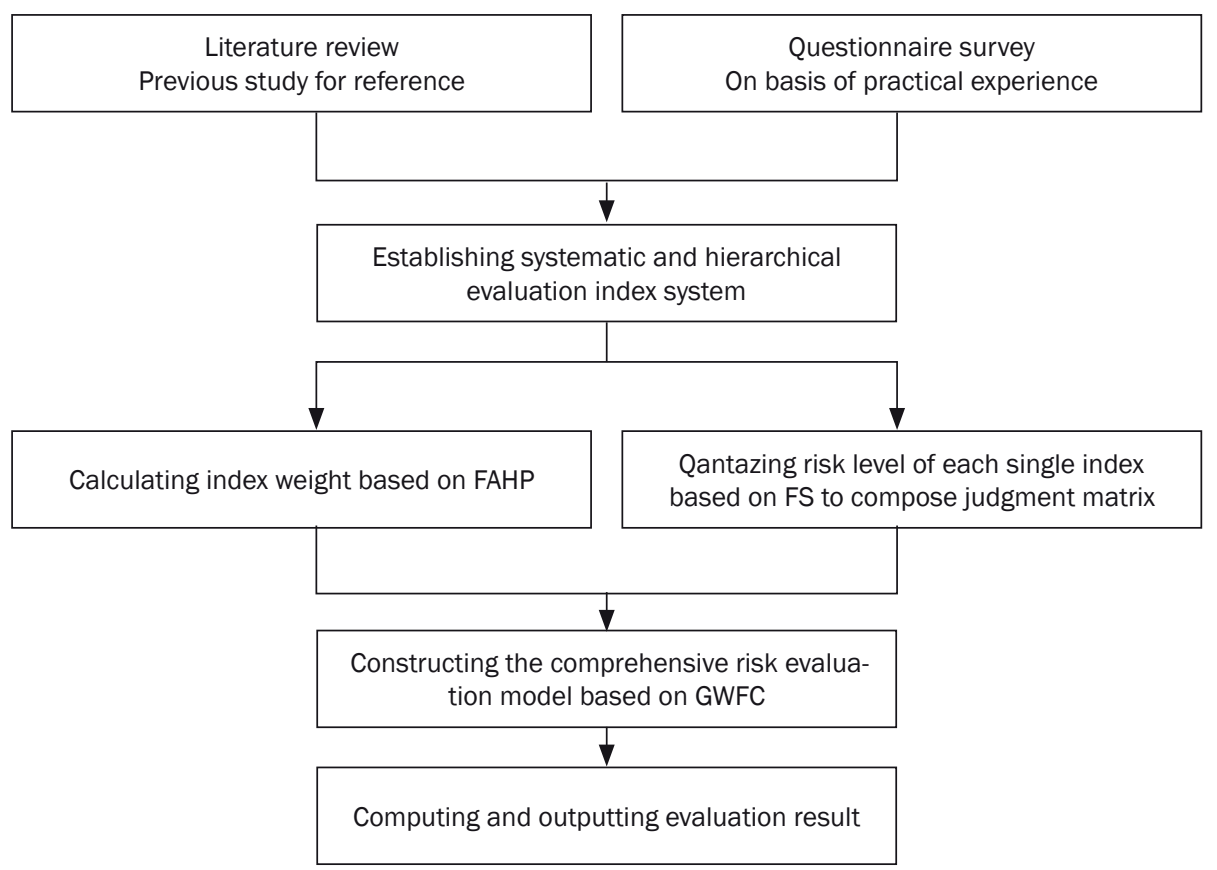

Figure 1 - Step diagram of risk evaluation based on GFWC 


\section{SOLUTIONS TO ACHIEVING TWO SUB-GOALS}

As just mentioned in Section 3, the FAHP method is introduced to calculate the index weight (aiming at getting $\eta_{j}$ ), and also the FS method is introduced to quantize the risk level of each single index (aiming at getting $\left.f_{j}^{k}\left(x_{i j}\right)\right)$. In this section, the solutions to achieving the two sub-goals will be respectively proposed after explaining the featured advantages of the two recommended methods.

\subsection{The FAHP based approach to index weight}

Indeed, it is not difficult to obtain index weight by using some multi-criteria decision-making (MCDM) methods. At present, some system analysis methods, such as Delphi method [40], Method of paired comparison [41], Analytic Hierarchy Process (AHP) [42], Fuzzy Analytic Hierarchy Process (FAHP) [43], Analytic Network Process (ANP) [44], Technique for Order Preference by Similarity to Ideal Solution (TOPSIS) [45], Entropy method $[46,47]$ and Principal Component Analysis [48, 49], were mostly used to determine the factor weight in many literatures. In this paper, an FAHP is chosen as the preferred tool to calculate the weight of risk evaluation index.

The well-known AHP [42], which is one of the most used MCDM approaches, is a structured multi-criteria technique for organizing and analyzing complex decisions including many conflicting criteria [50]. Despite the convenience of AHP in handling both quantitative and qualitative criteria of MCDM problems based on decision makers' judgments, fuzziness and vagueness existing in many decision-making problems may lead to imprecise judgments of decision makers in conventional AHP approaches [51]. In this case, FAHP began to appear. By absorbing ideas of fuzzy sets theory [52], the FAHP technique can be viewed as an advanced analytic method developed from the traditional AHP [50]. The linguistic scale used in FAHP is a more detailed and flexible way of making the method much more adaptive.

There have been many FAHP applications which use the fuzzy set theory to incorporate the linguistic variables into these methods [50]. For example, the detailed algorithms proposed by Kahraman et al. [50], Laarhoven and Pedrycz [53], Tseng et al. [54], and Zhang et al. [55].

Depending on the advantages of FAHP, now there follow the implementation steps of using the method to get the index weight. After choosing the evaluation indices (setting up an index system), the main four steps involved in FAHP are summarized to calculate the index weight under the framework of Zhang's [55] algorithm:

1) Construct the fuzzy complementary judgment matrix A using 0.1 0.9 scales;
2) Adjust the fuzzy complementary judgment matrix A to fuzzy consistent matrix $\widetilde{A}$;

3) Get a synthesized fuzzy consistent matrix $\bar{A}$ in case there are multiple fuzzy consistent matrices $\widetilde{\mathrm{A}}_{i}(i=1,2, p, p$ is the number of $\widetilde{\mathrm{A}})$;

4) Calculate the weight of each index by dealing with the final fuzzy consistent matrix $\bar{A}$.

Specifically, using Xu's [56] and Yuan's [57] ideas for reference, a complete and specific approach to index weight based on the adopted FAHP has been given in the previous work [58], which can be referred to for details, including the meanings of the summarized steps and parameter settings for the steps. In the following case study, the index weight is calculated via the above just presented FAHP, strictly adopting the steps here and the detailed settings in [58].

\subsection{FS based approach to single index evaluation}

To be precise, usually the whiten weight function $f_{j}^{k}(\cdot)$ is structured according to the numerical characteristics of the indicators of cluster object, and is used to quantize the index risk level indicated by $f_{j}^{k}\left(x_{i j}\right)$, which is the whiten weight value of the $j$-th index concerning the $k$-th grey class. However, in most cases, it is not possible to structure a complete and accurate function for lack of quantitative judgment standard, making the bottleneck in an assessment. To overcome the defect, the fuzzy statistic method instead of constructing whiten weight function is introduced here to evaluate the index risk.

Accordingly $[59,60]$, the probability and fuzzy set theories are used to handle two different types of uncertainty. The probability theory is utilized to study the stochastic features of a certain phenomenon. Each event itself has a distinct meaning and no uncertainty. However, due to the lack of sufficient conditions, the outcome for a certain event to occur during a process cannot be determined. Fuzzy set theory is the base for people to study membership relationships from the fuzziness of phenomena. In the fuzzy set theory, the concept or event itself does not have a clear definition. For example, "a tall man" - how tall he is is not defined. And whether certain phenomena belong to this concept is difficult to determine. It is called fuzziness here: the uncertainty involved in the classification due to the imprecise concept definition, which is rooted in the existence of transitions between two phenomena. Such transitions make it possible for the decision-makers to label the phenomena into either this or that class.

Combining the advantages of the two theoretical tools, a fuzzy statistic (FS) process is used to estimate the degree of membership or membership function, whose purpose is to use a deterministic approach to study the uncertainties. After executing $n$ experiments ( $n$ is the total number of experiment times) and 
recording $n^{A}\left(n^{A}\right.$ is the number of times when an index is judged belonging to fuzzy set $A$ ), the membership frequency (denoted by $F$ ) of the index belonging to fuzzy set $A$ can be calculated. The theoretical mathematical model is:

$F=\frac{n^{A}}{n}$

As the total number of experiment times increases, $F$ may stabilize. The stabilized membership frequency is the degree of membership for the index belonging to $A$.

Depending on FS principles and its easy-operation characteristic, there follows the operational approach to index evaluation. As mentioned above, $r_{i j}^{k}$, the membership to the $k$-th grey class about the $j$-th index concerning the $i$-th evaluation object, is capable of expressing the risk level judgement of the considered index. Meanwhile, through the above analysis, FS provides a flexible way to the degree of membership for an index belonging to a grey class. Thus, on the basis of FS principle and in the light of some specific FS usage related literature [61, 62], $r_{i j}^{k}$ can be successfully obtained by Equation 5:

$r_{i j}^{k}=\frac{N^{k}}{N}$

where the subscript $i$ refers to the $i$-th studied object; $N^{k}$ represents the number of times when the $j$-th index belongs to the $k$-th grey class, $N$ represents the total number of experiment times.

After getting $r_{i j}^{k}$, Equation 2 can be realized.

\section{AN APPLICATION CASE}

The constructed GFWC model, together with the proposed two key link solutions, will be applied to comprehensively evaluate the risk of nautical navigational environment of the Qiongzhou Strait in this section, which will lead to a quantitative risk assessment result of the concerned object as well as test the model availability.

\subsection{Glance at Qiongzhou Strait}

Geographically, the Qiongzhou Strait is a narrow exchange passage of water between the South China Sea (SCS) and the Beibu Gulf, which is a coastal embayment adjacent to SCS [63, 64], as shown in Figure 2. Centered at $20^{\circ} 09^{\prime} \mathrm{N} 110^{\circ} 16^{\prime} \mathrm{E}$ [65], the Qiongzhou Strait is about $70 \mathrm{~km}$ long and $30 \mathrm{~km}$ wide, and with a maximum depth of $120 \mathrm{~m} \mathrm{[64]} \mathrm{and} \mathrm{the} \mathrm{nar-}$ rowest width of only $18 \mathrm{~km}$ [66].

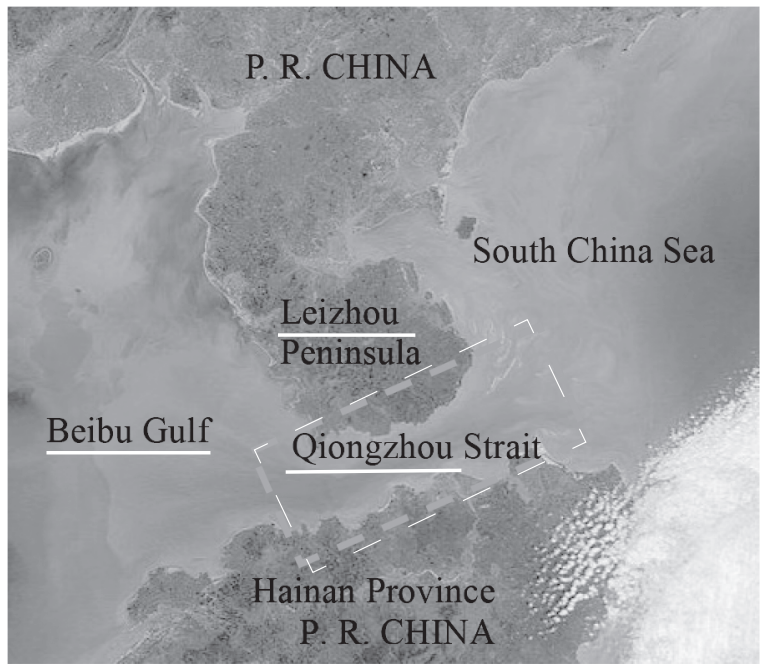

Figure 2 - Location of the Qiongzhou Strait

\subsection{Risk evaluation index system and the FAHP based index weight}

Above all, what the nautical navigational environment is shall be described to help establish the risk evaluation index system.

Actually, there is no single, accurate and acknowledged definition on nautical navigational environment. Accordingly [67, 68, 1-3], the nautical navigational environment is considered to refer to various external conditions necessary for water activities of a ship or other types of facilities. It is understood that the nautical navigational environment is a general saying of all sorts of natural and social factors affecting ship or facility safety of activities. Natural attribute refers to the objective natural conditions largely independent of the influence of human activity, such as the geographic position, meteorological and oceanographic conditions, geographical waterway length, bending, depth, etc. While social attribute refers to all kinds of hardware and soft environments created through human efforts for the convenience of water traffic, such as the navigational aids marking a navigable channel width, the number of ships and other types of facilities acting in the channel, the obstacles (e.g. shipwrecks, abandoned fishing nets, etc.) affecting safety of activities, the kinds of architectures above/below water surface and alongside the waterway (e.g. the bridges, piers, floating type wharfs, ...), etc.

Corresponding to the above mentioned general saying, the particulars of the Qiongzhou Strait nautical navigational environment were well presented in the related literature [69-72].

Then follows the discussion about setting up the evaluation index system and getting the index weight. The risk evaluation index system is the foundation of an assessment work from the perspective of MCDM. 
On the basis of the general saying about the nautical navigational environment, the scholars used to group nautical navigational environment attributes into three categories: natural environment, channel condition, and traffic environment [73, 74], for setting up a risk evaluation index system. Referring to their contributions [73, 74] and consulting 29 experts, the traditional three categories were used to group nautical navigational environment attributes of the Qiongzhou Strait. Furthermore, though a nautical navigational environment system consists of various factors (as stated in the above paragraph), the importance of the factors is not equal. Therefore, only several main factors are selected together to represent the system and are used for evaluation [2, 3, 73, 74]. The selected factors are also called indices. Based on the practical experiences from the cited references and combining the 29 experts' decisions, the main nine factors, visibility, wind, current, width, depth, cross, traffic flow, obstacles, navigational aids, are selected as the ultimate indicators for setting up the evaluation index system. Since, for a hierarchical express, the risk evaluation index system of Qiongzhou Strait navigational environment had already been established in the previous work [58], the constructed index system is quoted and listed in Table 1. It is noted that the determined indices hold the following meanings:

1) Visibility: considering the number of days of restricted visibility out of the whole year.

2) Wind: considering the number of days of strong wind out of the whole year.

3) Current: considering the average impact of instable flow out of the whole year.

4) Width: considering the ratio: mean ship length overall (LOA) - width of navigable channel. Here, "ship" refers to the ones that passed the Qiongzhou Strait from out of the whole year; and different from the geographical name, the "navigable channel" refers to the ship traffic lanes described in the ship routing system of the Qiongzhou Strait and identified by navigational aids.

5) Depth: considering the ratio: mean ship draft water depth of the navigable channel. Similarly, "ship"" and "navigable channel" hold the same meanings as given in 4).

6) Cross: considering a mean cross angle of ship routes. Similarly, "ship" holds the same meaning as given in 4).

7) Traffic flow: considering the mean number of ships within the navigable channel per day, out of the whole year. The index is chosen as to represent ship traffic density in the navigable channel.

8) Obstacles: considering the obstacle distribution in or nearly around the navigable channel.

9) Navigational aids: considering whether the navigational aids are sufficiently equipped to identify the navigable channel and guide the ships.
What is more, the weights of selected indices had been calculated by applying FAHP method (refer to [58] for details), which are also quoted and listed in Table 1.

Table 1 - Risk evaluation index system and index weight

\begin{tabular}{|c|c|c|c|}
\hline Target index & $\begin{array}{l}\text { First class } \\
\text { indices }\end{array}$ & $\begin{array}{c}\text { Second } \\
\text { class indices }\end{array}$ & Weights [\%] \\
\hline \multirow{9}{*}{$\begin{array}{c}\text { Nautical } \\
\text { navigational } \\
\text { environment } \\
\text { of Qiong- } \\
\text { zhou Strait }\end{array}$} & \multirow{3}{*}{$\begin{array}{c}\text { Natural } \\
\text { environment }\end{array}$} & Visibility & 10.02 \\
\hline & & Wind & 7.83 \\
\hline & & Current & 13.46 \\
\hline & \multirow{3}{*}{$\begin{array}{l}\text { Channel } \\
\text { condition }\end{array}$} & Width & 11.74 \\
\hline & & Depth & 10.98 \\
\hline & & Cross & 9.28 \\
\hline & \multirow{3}{*}{$\begin{array}{c}\text { Traffic } \\
\text { environment }\end{array}$} & Traffic flow & 11.99 \\
\hline & & Obstacles & 9.90 \\
\hline & & $\begin{array}{l}\text { Navigation } \\
\text { aids }\end{array}$ & 14.78 \\
\hline
\end{tabular}

\subsection{Single factor evaluation: index risk membership based on FS}

Featured with membership degree to a certain risk level, risk evaluation of single index is carried out via FS.

\section{Risk grading}

Currently, while doing an evaluation work, for example [2] and [3], there are five risk grades indicated by 5 uncertain concepts such as Low, Less low, Moderate, Less high and High, which can be treated as grey categories according to grey theories. Thus, five grey concepts symbolized with $G_{1}$ to $G_{5}$ are employed here to assess the navigational environment qualitatively. The correspondence between the grey language and symbols are listed in Table 2.

Table 2 - Correspondence between the grey languages and risk level symbols

\begin{tabular}{|c|c|c|c|c|c||}
\hline \hline Symbols & $G_{1}$ & $G_{2}$ & $G_{3}$ & $G_{4}$ & $G_{5}$ \\
\hline \hline $\begin{array}{c}\text { Grey } \\
\text { language } \\
\text { describing } \\
\text { risk level }\end{array}$ & Low & $\begin{array}{c}\text { Less } \\
\text { low }\end{array}$ & Moderate & $\begin{array}{c}\text { Less } \\
\text { high }\end{array}$ & High \\
\hline
\end{tabular}

Index membership to a certain risk level

As stated above, evaluation of individual index will be accomplished by FS. After an FS procedure, the original survey result of index risk level is listed in Table 3. Note that the number filled in Table 3 means the number of individuals who judged the specific index of the corresponding risk level. By using Equation 5, index membership to a certain risk level indicated by $r_{i j}^{k}$ was listed in Table 4. Note: $i=1$, since there is only one object: the Qiongzhou Strait. 
Table 3 - Survey result of index risk level by fuzzy statistics

\begin{tabular}{||c|c|c|c|c|c|}
\hline \multirow{2}{*}{ Indices } & \multicolumn{5}{|c|}{ Risk level } \\
\cline { 2 - 6 } & Low & $\begin{array}{c}\text { Less } \\
\text { low }\end{array}$ & Moderate & $\begin{array}{c}\text { Less } \\
\text { high }\end{array}$ & High \\
\hline \hline Visibility & 0 & 0 & 5 & 20 & 4 \\
\hline Wind & 0 & 0 & 13 & 14 & 2 \\
\hline Current & 7 & 18 & 3 & 1 & 0 \\
\hline Width & 0 & 11 & 14 & 3 & 1 \\
\hline Depth & 0 & 8 & 12 & 8 & 1 \\
\hline Cross & 0 & 2 & 18 & 9 & 0 \\
\hline Traffic flow & 0 & 2 & 12 & 14 & 1 \\
\hline Obstacles & 0 & 6 & 11 & 11 & 1 \\
\hline Navigation aids & 9 & 16 & 4 & 0 & 0 \\
\hline
\end{tabular}

\subsection{Comprehensive risk evaluation based on GFWC}

After the above steps, the grey fixed weight cluster coefficient can be calculated by using Equation 2 .

$$
\begin{aligned}
& \sigma_{i=1}^{k=1}=\sum_{j=1}^{n=9} f\left(x_{i j}\right) \cdot \eta_{j}=0.078931 \\
& \sigma_{i=1}^{k=2}=\sum_{j=1}^{n=9} f\left(x_{i j}\right) \cdot \eta_{j}=0.275181 \\
& \sigma_{i=1}^{k=3}=\sum_{j=1}^{n=9} f\left(x_{i j}\right) \cdot \eta_{j}=0.333616 \\
& \sigma_{i=1}^{k=4}=\sum_{j=1}^{n=9} f\left(x_{i j}\right) \cdot \eta_{j}=0.278192 \\
& \sigma_{i=1}^{k=5}=\sum_{j=1}^{n=9} f\left(x_{i j}\right) \cdot \eta_{j}=0.034621
\end{aligned}
$$

where, as defined above, $f_{j}^{k}\left(x_{i j}\right)$ is equal to $r_{i j}^{k}$, which means the risk level membership of indices (shown in Table 4), $\eta_{j}$ means the weight of index $j ; i=1$ denotes there is only one studied object: the Qiongzhou Strait; $j=1,2, \ldots, n$ represents $n$ indices $(n=9) ; k=1,2,3,4,5$ represents the number of grey categories.

Concerning the studied object, the above five numerical values show the risk level memberships to the five grey categories used in the paper for qualitative evaluation. The value of $\sigma_{i=1}^{k}$ reflects the tendency of determining nautical navigational environment risk of the Qiongzhou Strait at the $k$-th grade. From the above results, the biggest element $\sigma_{i}^{k^{*}}$ among $\sigma_{i}$ is $\sigma_{i=1}^{k=3}$. Thus, according to the maximum membership principle, it is considered that the navigational environment risk of the Qiongzhou Strait can be determined at the $3^{\text {rd }}$ grade. That is to say, the navigational environment risk of the Qiongzhou Strait is determined at a "Moderate" level, symbolized by $\mathrm{G}_{3}$.

Through the application, the model's availability is validated. In general, the proposed model as well as the implementation step are workable, which can explore the collected experts' knowledge mathematically, quantify the weight of each index and the risk level, and finally lead to a comprehensive risk evaluation of nautical navigational environment.

\section{CONCLUSION}

In this paper, a GFWC risk assessment model is proposed, and the implementation steps of the model are presented. Concerning two key steps, the FAHP and FS are adopted to fulfilling two sub-goals. The FAHP based approach to index weight is given due to the linguistic scale based adaptability of the algorithm; the FS based approach to single index evaluation is put forward to avoid the difficulty of building whiten weight functions. The designed solutions to achieving two sub-goals aim at ensuring the availability and feasibility of the model.

The proposed model and specific approach steps are applied to comprehensive evaluation of the risk of nautical navigational environment of the Qiongzhou Strait. In the application case study, the evaluation

Table 4 - Risk level memberships of the indices

\begin{tabular}{|c|c|c|c|c|c|c||}
\hline \hline \multicolumn{2}{|c|}{ Memberships $\left(r_{i j}^{k}\right)$} & \multicolumn{6}{|c|}{ Risk level (described by grey language) } \\
\cline { 2 - 7 } & Visibility & Low & Less low & Moderate & Less high & High \\
\hline \hline \multirow{4}{*}{ Indices } & Wind & 0 & 0 & 0.1724 & 0.6897 & 0.1379 \\
\cline { 2 - 7 } & Current & 0.2415 & 0.6210 & 0.1035 & 0.0340 & 0.0690 \\
\cline { 2 - 7 } & Width & 0 & 0.3793 & 0.4828 & 0.1034 & 0.0345 \\
\cline { 2 - 7 } & Depth & 0 & 0.2759 & 0.4137 & 0.2759 & 0.0345 \\
\cline { 2 - 7 } & Cross & 0 & 0.0690 & 0.6207 & 0.3103 & 0 \\
\cline { 2 - 7 } & Traffic flow & 0 & 0.0690 & 0.4138 & 0.4827 & 0.0345 \\
\cline { 2 - 7 } & Obstacles & 0 & 0.2069 & 0.3793 & 0.3793 & 0.0345 \\
\cline { 2 - 7 } & Navigation aids & 0.3103 & 0.5517 & 0.1380 & 0 & 0 \\
\hline
\end{tabular}


index system is structured scientifically through literature review and expert investigation and the relative weight of each index is calculated via FAHP; Index membership degree of every grey class is obtained by FS; Nautical navigational environment risk of the Qiongzhou Strait is comprehensively determined at a "Moderate" level according to the principle of maximum membership degree. Risk evaluation of the studied object can provide theoretical reference for implementing the targeted risk control measures.

The model's availability is validated through the application case. The achieved quantitative evaluation result shows that the constructed GFWC risk assessment model as well as the presented steps are workable in case of incomplete information (lack of observations, limited survey samples, etc.). Besides, the adoptions of probability and statistic theory, fuzzy theory aim at solving the bottlenecks in case of uncertainty (e.g., randomness, fuzziness), which will give the model a better adaptability and executability.

Whereas it is obvious that the proposed GFWC risk assessment model utilizes index system and expert judgement as the primary basis. Thus, the risk evaluation result of nautical navigation environment is closely related to the choice of evaluation index and expert knowledge. Completeness of the index system, the quantity and quality of the questionnaires obviously affect the evaluation result accuracy. Thus, in subsequent studies the following issues will be emphasized and implemented to obtain more scientific appraisal results: data-collection (by consulting literature and experts, etc.), comparison analysis (e.g. comparison to results of other models, application of the proposed model to nautical navigational environment of other waters, etc.), completeness of index system, quantitative evaluation standards for indices, and model improvement (by introducing other methods), etc.

\section{ACKNOWLEDGEMENTS}

This work is supported by: (1) the Fundamental Research Funds for the Central Universities (specifically supported by the self-determined and innovative research funds of Wuhan University of Technology, Grant No. 2014-JL-010), (2) the National Natural Science Foundation of China (Grant No. 51379170), and (3) the Key Project in the National Science \& Technology Pillar Program (Grant No. 2015BAG20B05). Special thanks go to the research projects for their infrastructural and financial support. Sincere appreciation goes to the scholars of references for their outstanding contributions.

田延飞，博士生 1,2

(通讯作者)

邮箱：feifei_whut@163. com

孙雪铖, 硕士 ${ }^{3}$ 邮箱：1061958377@qq. com

陈立家，博士 1,2

邮箱：navisky@qq.com

黄立文，博士 ${ }^{1,2}$

邮箱: 1whuang@whut.edu.cn

1 武汉理工大学, 航运学院

中国，武汉 430063，武昌区，和平大道，1178号

2 内河航运技术湖北省重点实验室

中国，武汉 430063，武昌区，和平大道，1178号

3 广州海事局，南沙海事处

中国，广州 511458，南沙区，港口大道，620号

基于灰色定权聚类的海上通航环境风险评估

摘要：为建立适合海上通航环境风险评估的数学模 型, 从而能够以量化形式系统地把握琼州海峡通航 环境风险特征, 基于灰色定权聚类方法构建了一种 风险评估模型, 并给出了其实现步骤。采用文献查 阅和专家调查的方式, 以科学建立评估指标体系。 设计采用模糊层次分析法计算各指标相对权重。为 避免构建白化权函数面临的困难, 设计采用模糊统 计方法得到各指标风险对每个灰类的隶属度。使用 所建立的模型, 根据最大隶属度原则, 判定琼州海 峡通航环境风险为 “中等” 水平。对琼州海峡通航 环境风险的综合评估能够为采取针对性的风险控制 措施提供理论参考。研究显示, 构建的基于灰色定 权聚类的风险评估模型及给出的实现步骤能够在不 完备信息下有效施行。文中提出的方案能够从数学 意义上发掘收集到的专家知识的内涵, 从而量化各 指标权重和风险等级, 并最终给出综合风险评估结 果。此外, 为克服不确定性这一瓶颈, 引入概率统 计理论、模糊理论, 使得构建的综合评估模型具有 更好的适应性和可执行性。

关键字：海上通航环境；风险评估；灰色定权聚类； 模糊层次分析法; 模糊统计

\section{REFERENCES}

[1] Zhang JF, Yan XP, Zhang D, et al. Safety management performance assessment for Maritime Safety Administration (MSA) by using generalized belief rule base methodology. Safety Science. 2014;63:157-167.

[2] Hu SP, Fang QG, Zhang JP, et al. Risk Assessment of Marine Traffic Safety in Coastal Water Area. Navigation of China. 2010;33(1):50-55. [in Chinese with English abstract]

[3] Xuan YS, Li FM, Hu SP, et al. Risk Assessment of Ship Navigation in Guangzhou Harbor. Navigation of China. 2013;36(4):96-99. [in Chinese with English abstract]

[4] Mi CM, Liu SF, Dang YG, et al. Study on grey entropy weight clustering decision-making. Systems Engineering and Electronics. 2006;28(12):1823-1844. [in Chinese with English abstract]

[5] Gong ZW, Forrest JYL. Special issue on meteorological disaster risk analysis and assessment: on basis of grey systems theory. Natural Hazards. 2014;71(2):9951000.

[6] Deng JL. Control problems of unknown system. Recent Developments in Control Theory \& Its Application 
- Proceedings of the Bilateral Meeting on Control Systems; 1981 Aug 10-12; Shanghai, China; 1982. p. 156-171.

[7] Deng JL. Control Problems of grey systems. Systems and Control Letters. 1982;1(5):288-294.

[8] Deng JL. The Grey Control System. Journal of Huazhong Institute of Technology. 1982;10(3):9-18. [in Chinese with English abstract]

[9] Shao M, Gong Z, Xu X. Risk assessment of rainstorm and flood disasters in China between 2004 and 2009 based on gray fixed weight cluster analysis. Natural Hazards. 2014;71(2):1025-1052.

[10] Xie NM, Liu SF, Zhan HB. On the selection of international cooperation key-technology projects based on grey cluster model. Proceedings of the 4th IEEE International Conference on Grey Systems and Intelligent Services; 2013 Nov 15-17; Macau, China; 2013. p. 366-370.

[11] Luo XW, Shu ZQ, Li J. Comprehensive Evaluation on Performance of PSA Blended Fabrics. Advanced Materials Research. 2013;821-822:317-320.

[12] Hu J, Xu LZ, Zhang JS. Modified grey clustering model on air quality assessment. Journal of Fujian Normal University (Natural Science Edition). 2012;28(1):4954. [in Chinese with English abstract]

[13] He LJ, Huang HK, Dong XY. GTrust: A Distributed Trust Model in Multi-Agent Systems Based on Grey System Theory. Lecture Notes in Computer Science; 2011. p. 274-279.

[14] Li YF, Mou HH, Lv K. Gray Clustering Evaluation Method of MIE on Combinative Weight-Fixing. Key Engineering Materials. 2011;455:369-372.

[15] Hua ET, Cao WW, Chen Y, et al. A gray fixed cluster method based on the Dempster-shafer evidential theory. Proceedings of the 2011 IEEE International Conference on Electronics, Communications and Control; 2011 Sep 9-11; Ningbo, China; 2011. p. 3482-3485.

[16] Tang JJ, Li CC. Post-evaluation method of highway meteorological disaster in flood seasons based on grey clustering and AHP. Highway. 2011;1:171-176. [in Chinese with English abstract]

[17] $\mathrm{Hu} \mathrm{LM}$, Zhang $\mathrm{CH}$, $\mathrm{Hu} \mathrm{CH}$, et al. Use of grey system for assessment of drinking water quality: a case study of Jiaozuo city, China. Proceedings of 2009 IEEE International Conference on Grey Systems and Intelligent Services; 2009 Nov 10-12; Nanjing, China; 2010. p. 803-808.

[18] Jiao JC, Ma SJ. Synthetical evaluation on the water quality of Yangtze River based on grey fuzzy clustering analysis. Journal of Nanyang Institute of Technology. 2010;2(4):94-97. [in Chinese with English abstract]

[19] Wang CL, Zhang JQ, Ning FG, et al. Grey Fixed Weight Clustering Method-Based Agricultural Drought Disaster Situations Assessment and Regionalization in Northwestern Liaoning Province. 2010 Chinese Perspective on Risk Analysis and Crisis Response - Proceedings of the 4th Annual Meeting of Risk Analysis Committee (RAC), China Association for Disaster Prevention; 2010 Aug 16-17; Changchun, China; 2010. p. 373-378.

[20] Zhang L, Chang J, Liu J, et al. Optimization Model of Whole Performances for Development Method Based on Gray Fixed Weight Clustering. Proceedings of the International Conference on Engineering and Business
Management 2010; 2010 Mar 24-26; Chengdu China; 2010. p. 1671-1673.

[21] Hu X, Zhou J, Huang P. On the ferro-graphic characterisation of wear debris in tribological system by grey fixed weight clustering. International Journal of Surface Science \& Engineering. 2010;4(4):448-464.

[22] Jian LR, Liu SF, Liu Y. The Selection of Regional Key Technology Based on the Hybrid Model of Grey Fixed Clustering and Variable Precision Rough Set. Proceedings of the 10th WSEAS International Conference on Systems Theory and Scientific Computation; 2010 Aug 20-22; Taipei, Taiwan; 2010. p. 54-59.

[23] Zhang FS, Diao ZF. Research on Grey Cluster Evaluation Model and its Application of University Core Competence. Proceedings of the 7th International Conference on Innovation \& Management; 2010 Jul 7-10; Penang, Malaysia; 2010. p. 1828-1832.

[24] Zhu GP, Wang LG. Grey clustering decision-making evaluation on indoor air quality. Safety \& Environmental Engineering. 2009;16(2):33-35. [in Chinese with English abstract]

[25] Ip WC, Hu BQ, Wong H, Xia J. Applications of grey relational method to river environment quality evaluation in China. Journal of Hydrology. 2009;379(3-4):284290.

[26] Zhang GY, Li XH, Tan QM. The Evaluation and Analysis of Development Vigor of the Cities Located in Yangtze River Delta Area. Proceedings of the 2008 ISECS International Colloquium on Computing, Communication, Control, and Management; 2008 Aug 3-4; Guangzhou, China; 2008. p. 730-734.

[27] Wang WL, Wang DD. The Regional Clusters Analysis on Development Situation of R\&D Industry in China. Advances in Management of Technology PT2 - Proceedings of the 2008 International Conference on Management of Technology; 2008 Aug 30-Sep 1; Taiyuan, China; 2008. p. 51-55.

[28] Zhang GY, Tan QM, Li XH. The Evaluation and Analysis of Development Vigor in Central Chinese Cities. Proceedings of the 5th International Conference on Innovation \& Management; 2008 Dec 10-11; Maastricht, The Netherlands; 2008. p. 240-244.

[29] Li XH, Tan QM, Zhang GY. Urban Sustainable Development of the Yangtze River Delta Area. Proceedings of the 2008 International Conference on Information Management, Innovation Management and Industrial Engineering; 2008 Dec 19-21; Taipei, Taiwan; 2008. p.185-189.

[30] Lin LW, Chen CH, Chang HC, et al. Applying the grey assessment to the evaluation system of ecological green space on greening projects in Taiwan. Environmental Monitoring \& Assessment. 2008;136(1-3):129-146.

[31] Wang YH, Dang YG, Wang ZX. Study on grey fixed weight clustering decision-making based on interval numbers. Proceedings of the 2007 IEEE International Conference on Grey Systems and Intelligent Services; 2007 Nov 18-20; Nanjing, China; 2007. p. 341-345.

[32] Zhang GY, Li XH, Tan QM. A study of sustainable development of Chinese central cities based on the grey fixed-weight clustering method. Proceedings of the 2007 IEEE International Conference on Grey Systems and Intelligent Services; 2007 Nov 18-20; Nanjing, China; 2007. p. 346-350. 
[33] Nie XX, Liu AM, Liu SX. The application of grey clustering decision in determining the rational open-pit limit of mining. Proceedings of the 2007 IEEE International Conference on Grey Systems and Intelligent Services; 2007 Nov 18-20; Nanjing, China; 2007. p. 841-844.

[34] Mi CM, Liu SF, Dang YG, et al. Study on grey fixed weight clustering decision-making based on entropy weight. Proceedings of the 2006 IEEE International Conference on Systems, Man, and Cybernetics; 2006 Oct 8-11; Taipei, Taiwan; 2006. p. 461-465.

[35] Xu HG, Liu ZH, Wang C. Grey fixed weight clustering model and causal factor analysis for evaluation of road safety grade. Progress in Safety Science and Technology Vol VI - Proceedings of the 2006 International Symposium on Safety Science and Technology; 2006 Oct 2427; Changsha, China; 2006. p. 2016-2021.

[36] [36] Li BJ, Liu SF. Studies on dynamic evaluating model for grey clustering and its application to a regional scientific-technical system. Proceedings of the 2005 IEEE International Conference Networking, Sensing and Control; 2005 Mar 19-22; Tucson, AZ, U.S.A.; 2005. p. 939-942.

[37] Liu ZB, Wang JS. Grey-clustering analysis of quality of underground water contaminated by leaching water in waste disposal area. Journal of Liaoning Technology University. 2004;23(3):423-425. [in Chinese with English abstract]

[38] Yu YW. Grey appraisal on the efficiency of China commercial banks. Proceedings of the 2003 International Conference on Management Science and Engineering; 2003 Aug 15-17; Atlanta, America; 2003. p. 16421646.

[39] He BF, Wang XY, He XJ, et al. Water quality evaluation method based on grey-clustering decision. Journal of Zhengzhou University (Engineering Science). 2002;23(1):10-13. [in Chinese with English abstract]

[40] Yuan HX, Wang NP, Shi D. Application of Delphi method for defining weights of the main influencing factors in submarine cabin air quality. Jouranal of Navy Medicine. 2004;25(4):295-297. [in Chinese with English abstract]

[41] Gong ZF. Method of paired comparison and its application in the research of psychology and education. Psychological Science. 2001;24(4):496. [in Chinese with English abstract]

[42] Saaty TL. The analytic hierarchy process. New York: McGraw-Hill Book Company; 1980.

[43] Buckley JJ. Fuzzy hierarchical analysis. Fuzzy Sets Systems. 1985;17:233-247.

[44] Saaty TL. Theory and Applications of the Analytic Network Process: Decision Making with Benefits, Opportunities, Costs, and Risks. Pittsburgh: RWS Publications; 2005.

[45] Hwang CL, Yoon K. Multiple attribute decision making - methods and applications: a state-of-the-art survey. Lecture Notes in Economics \& Mathematical Systems. 1981;186:21-112.

[46] Chen J, Liu Q, Qian H. Application of improved Nemerow index method based on entropy weight for groundwater quality evaluation. International Journal of Environmental Sciences. 2012;2(3):1284-1290.

[47] Wang LM, Zhang L, Han XM, et al. An improved affinity propagation clustering algorithm based on entropy weight method and principal component analysis. International Journal of Database Theory and Application. 2016;9(6):27-238.

[48] Han XH. Determination method of index weight based on principal component analysis. Journal of Sichuan Ordnance. 2012;33(10):124-126. [in Chinese with English abstract]

[49] Luo ZZ, Zhang FY. Application of Principal Component Analysis Method in Calculating the Weights of the Indexes of the Highway Nodes' Importance. Journal of Transportation Systems Engineering and Information Technology. 2005;5(6):78-81. [in Chinese with English abstract]

[50] Kahraman, C, Öztayşi, B, Sari iU, et al. Fuzzy analytic hierarchy process with interval type-2 fuzzy sets. Knowledge-Based Systems. 2014;59:48-57.

[51] Chen SJ, Hwang CL, Hwang FP. Fuzzy Multiple Attribute Decision Making: Methods and Applications. Berlin: Springer-Verlag; 1992.

[52] Zadeh LA. Fuzzy sets. Information \& Control. 1965;8(3):338-353.

[53] Laarhoven PJM, Pedrycz W. A fuzzy extension of Saaty' S priority theory. Fuzzy Sets Systems. 1983;11:229241.

[54] Tseng ML, Lin YH , Chiu AS, et al. Fuzzy AHP - approach to TQM strategy evaluation. Industrial Engineering \& Management Systems. 2008;7(1):34-43.

[55] Zhang JJ. Fuzzy Analytical Hierarchy Process. Fuzzy Systems and Mathematics. 2000;14(2):80-88. [in Chinese with English abstract]

[56] Xu ZS. An algorithm for priority of fuzzy complementary judgement matrix. Journal of Systems Engineering. 2001;16(4):311-314. [in Chinese with English abstract]

[57] Yuan HQ,Yang Y, Fan JF, et al. Application of Fuzzy Analytic Hierarchy Process to Bridge State Comprehensive Assessment. Journal of Wuhan University of Technology (Transportation Science \& Engineering). 2005;29(6):906-909. [in Chinese with English abstract]

[58] Tian YF, Sun XC. Risk evaluation index system of navigation environment of Qiongzhou strait based on FAHP. Proceedings of the 3rd International Conference on Transportation Information and Safety; 2015 Jun 25-28; Wuhan, China; 2015. p. 729-731.

[59] Center for Assessment and Monitoring of Forest and Environmental Resources, University of California at Berkeley: Fuzzy Statistics. [cited 2016 Nov 20]. Available from: http://nature.berkeley.edu/ penggong/ textbook/chapter8/html/sect865.htm

[60] Yu XJ, Zhang ST, Ma L K. Research on Seasonal Floods Based on the Fuzzy Statistical and Fractal Methods. China Rural Water and Hydropower. 2009;(7):65$67+71$. [in Chinese with English abstract]

[61] Chen SY, Wang SY, Wang GY, et al. Determination of relative dependence function of flood season by direct fuzzy statistic test. Advances in Science \& Technology of Water Resources. 2003;20(1):5-7+69. [in Chinese with English abstract]

[62] Fan L, Lei YJ. Intuitionistic fuzzy statistic adjudging and decision making. Control and Decision. 2011;26(3):357-362. [in Chinese with English abstract] 
[63] Wang QY, Wang XW, Xie LL, et al. Observed water current and transport through Qiongzhou Strait during August 2010. Chinese Journal of Oceanology and Limnology. 2014;32(3):703-708.

[64] Chen CL, Li PL, Shi MC, et al. Numerical study of the tides and residual currents in the Qiongzhou Strait. Chinese Journal of Oceanology and Limnology. 2009;27(4):931-942.

[65] Shi MC, Chen CS, Xu, QC, et al. The Role of Qiongzhou Strait in the Seasonal Variation of the South China Sea Circulation. Journal of Physical Oceanography. 2002;32(1):103-121.

[66] Xu XC, Xin JW, Liang GF, et al. Observation and Analysis of Sea Surface Wind over the Qiongzhou Strait. Journal of Tropical Meteorology. 2011;27(1):118-124. [in Chinese with English abstract]

[67] Wu ZL, Zhu J. Marine Traffic Engineering (second edition). Dalian: Dalian Maritime University Press; 2004.

[68] Dissemination of science: The concept of nautical navigational environment and its constituting elements. 2016 Jun 9 [cited 2016 Nov 20]. Available from: http://sanwen8.cn/p/132qBOl.html [in Chinese]
[69] Huang J. Comments on the oil spill emergency response ability of Qiongzhou Strait. World Shipping. 2013;36(3):15-17. [in Chinese]

[70] Li T. A Study on the problems of Qiongzhou Strait Traffic Management and Countermeasures [Master's thesis]. Wuhan: Wuhan University of Technology; 2013. [in Chinese with English abstract]

[71] Liu ZM, Kang Z. Safety control of ships navigating in the Qiongzhou Strait in foggy weather. China Marine Safety. 2011;(2):28-30. [in Chinese]

[72] Zhu WH. The role of VTS in the safety of ship navigation in the Qiongzhou Strait. China Water Transport. 2009;9(8):58-59. [in Chinese]

[73] Sun C, Nie DR, Zhang JP, et al. Risk Assessment of Navigation Environment of Waigaoqiao Waters. Navigation of China. 2012;35(2):68-71. [in Chinese with English abstract]

[74] Chen H, Liu BS, Weng GL. Comprehensive Risk Assessment of shipping Environment in Luoyuan Bay. Navigation of China. 2013;36(4):86-91. [in Chinese with English abstract] 